\title{
Epistemological Advances in Studying the Demography of Ageing
}

\author{
Uche C. Isiugo-Abanihe and Elias Olukorede Wahab* \\ Department of Sociology, University of Ibadan, Ibadan, Nigeria \\ *Department of Sociology, Lagos State University, Ojo, Lagos, Nigeria
}

KEYWORDS Demography of Ageing. Epistemological Issues. Anthropological-sociological Approaches. Gerontological Research. Methodological Triangulation

\begin{abstract}
This paper identified why many of the social science research guidelines had to be Changed in demography of ageing research. Therefore, attempts were made in this At re-focusing the methodological requirements in demography of ageing research.Methodological triangulation was used to collect data. This include questionnaire, focus Group discussion, in-depth interviews, case histories and documentary analysis. This was to Provide data on both social gerontology and demography of ageing. The paper interviewed More female respondents than their male counterparts. The study discovered that older persons who worked in the informal sectors of the economy Were more economically better than those who worked in the formal sectors. It was also Discovered that gerontological researches are more time consuming than fertility researches. The paper concludes that demography of ageing research is probably easier in developed Countries than in developing countries. The paper emphasized a shift in focus to the impact of old age on the older persons
\end{abstract}

\section{INTRODUCTION}

Over the past few years, the world's population has continued on its remarkable path from a state of high birth and death rates to one characterized by low birth and death rates as expounds in the demography transition theory (DTT). This has led to an astronomical increase in the population of older persons. Presently the global life expectancy is at 66 years. This current demographic revolution is expected to continue unabated into the coming centuries. This has given rise to a greater need for anthropological, sociological as well as survey methods of research and to provide modifications to existing methods because of the great sensitivity of the subject. In fact, only very few research on older persons has been undertaken in Nigeria even by the anthropologists (Wahab 2005). Part of the reasons for this, is the general belief that older persons have no place in societal development (Akeredolu-Ale 2003). Other reasons are twofolds. The first is that older persons are regarded as social misfits with little energy left for development. The second is that, arising from the nature of society; they had difficulty in being catered for by the government.

Corresponding author:

Dr. Elias Olukorede Wahab

Department of Sociology, Lagos State University,

P. M. B. 1087, Apapa, Lagos, Nigeria

Telephone: 234-802-305-4348, 234-805-307-7244

E-mail: eliasphd@yahoo.com
The few studies have been conducted by sociologists, who tend to examine basically the traditional versus modern care of the older persons. The lack of attention to the subject in Nigeria is shown by the fact that there exist no governmental policy on the older persons and scholars tend to run away due to the special and delicate nature of the subject. Therefore, there is dearth of published research on the situations of the older persons. If there had been, researcher would have possessed a greater armoury of methodologies and more substantial body of knowledge on demography of ageing.

Although, the researchers best equipped to undertake investigation of demography of ageing were those who had been working in the areas of geriatrics, fertility and mortality, yet there were problem. The first was that such researchers had been very reluctant to investigate the older persons even when involved in the study of mortality. The second is that medical doctors working on geriatrics had limited scope into the social contexts of ageing. It also become obvious to demographers that national census necessary for government planning was not regular. The third point is that demography of ageing research has proved in practice to differ more from fertility research than was at first appreciated. Compared with the situation of elderly persons in developed countries, the living profile of the aged population in developing countries is not well understood, due to the paucity of necessary data. Although an increasing number of surveys on the elderly 
have recently been conducted in various developing countries, information gathered from these surveys is not only fragmentary but also insufficient to fully understand the status of the elderly and the nature of problems facing them. In addition, the methodological strategy and the scope of such surveys need to be further improved with a view to facilitating cross comparative studies (Kinsella, 1990). As the level of economic development advances, the pattern of allocation of support changes from informal to formal support (Cowgill and Holmes 1972). This erosion in traditional support systems for the elderly has serious social and economic implications, which the present study sought to unravel. In the next section, we briefly outline the nature of existing fertility research, to demonstrate the changes that have to be made to fertility research methodology before it can get satisfactory information about demography of ageing.

First, however, it is necessary to identify the major features under demography of ageing. It is estimated that one out of every ten persons is now 60 years or above, by 2050 , one out of three persons will be 60 years or older. The older population itself is ageing. The oldest old ( 80 years or older) is the fastest growing segment of the older population. They currently make up 11 percent of the $60+$ age group and will grow to 19 percent by 2050 . In fact, the number of centenarians (aged 100 years or older) is projected to increase to 15 -fold from approximately 145,000 in 1999 to 2.2 million by 2050 . The majority of older persons ( 55 percent) are women. Among the oldest old, 65 percent are women. As the tempo of ageing in developing countries is more rapid than in developed countries, developing countries will have less time than the developed countries to adapt to the consequences of population ageing.

Researching on demography of ageing is probably easier in developed countries than in developing countries. One reason is that government in the former has enough record of older persons. This takes the form of social security to cater for the needs of this special population. Added to this are the social roles played by them in reducing social deviance. Perhaps related to this is the trend among western scholars to try green areas. Nigeria will experience a steep rise in its elderly population in the coming decades. In the 80 years between 1911 and 1991, the elderly population of Nigeria has gone from 1.21 to 4.60 million. By the year 2000, the projected elderly population was 7.25 million and by 2025 , the absolute number of the elderly population will be 17.62million (UNFPA 1998).

Literature on the elderly in Nigeria is scarce, although social scientists have started to give increasing attention to the problem. The government has not yet launched any formal programme for the welfare of the elderly. Some recent small-scale surveys show a depressing picture. Findings from recent micro level survey indicate that all is not well for the country's elderly population. So far, they have been supported mainly by their adult children, but owing to deteriorating economic conditions, this support may not be expected to continue for long (UNFPA 1998). In the wake of urbanization, modernization and the participation of women in economic activity outside the home, the elderly of Nigeria are being exposed to a situation in which they will lose their age long high status in society (Ogunbodede 1998).

In a study of the elderly in Nigeria, Ogunbodede (1998) contends that boredom experienced during old age might result in the elderly people suffering infirmity. According to him, retired and elderly people should be engaged in some variety of games, learning of crafts among others. He stresses that informal activity with friends and relatives made life more satisfying for the elderly. Adebagbo (1978: 150) notes that only a few old people's homes exist in Nigeria, with one in Ibadan, Benin and two in Lagos. Indeed, institutional care of the elderly in Nigeria is a recent phenomenon. And as Adegbagbo reports, the majority of the inmates in these institutions are destitutes with no known traceable relations. In sum, the above review reflects the growing number of the elderly population in Nigeria and the lack of adequate care for them.

An Anthropological - Sociological and Demographic approaches to the study of fertility

In several fertility studies in $60,70 \mathrm{~s}, 80 \mathrm{~s}, 90 \mathrm{~s}$, there were approaches tailored after behaviuoural studies. Literature study used to be the foundation of such approach. This was then followed by small-scale anthropological investigations to assess the picture from the literature review and to identify the green areas to be explored using survey approach. This is followed by the formation of questionnaire to be administered in the local language of respondents. This brought about the epistemological problem in terms of translating vernacular to English 
language. This is taking cognizance of education, religion, marital status, rural-urban residence among other socio-economic measures( Khasiani 1991; Bankole 2000).

One of the prerequisites for a successful survey was the use of extensive approaches including formal meetings with the community to be studied. This will enlist the services and support of town leaders. One of the reasons is to explain the need for the research, solicited their agreement and at times going as far as memorandum of understanding.

There is usually the problem of sampling techniques and procedures especially in rural areas. Eventually, researchers were forced to use cluster or stratified sampling techniques. The interviewer was recognized when visiting a household and all its members and neighbours were aware of just what was taking place. There was the use of supervisors to cross check the returns of the interviewers and maintain standards (Wahab 2005).

The interviewers were usually from the same sub-ethnic group but not from immediate areas. There was the employment of trustworthy people for coding, data processing and analysis.

Experience in the investigation of demography of ageing demonstrates how many of these apparently universal social science research guidelines had to be changed (Wahab 2005).

Researching demography of ageing in Nigeria

The original research aimed at finding the various socio-economic and demographic implications of the ageing process involved the collection of descriptive data on both the respondents and their immediate families (Wahab 2005). However, it was very difficult tracking down their children. This has obvious implications.

It was soon to be discovered that there were very little relevant literature to draw upon, and that studies elsewhere, especially in the developed countries, were not very useful. Thus, the need for preliminary anthropological work was stronger than in fertility studies. It was also later decided to locate the older persons in clusters in form of old peoples' homes. This is to ensure group complementarity (Wahab 2005).

There was also the need to keep community excitement and interest at the minimum. This is to increase the willingness of the target population to meet the researchers(Akeredolu-ale 2003).

Unlike in fertility surveys, the critical ingredient for success proved to be the calibre of the interviewer, not merely in terms of intelligence, training and competence, but also in personality (patience). It was noticed that an interview that would take one hour in fertility surveys could take three or more hours in demography of ageing. Yet the older persons had less time to spare. Then the interviewers needed to inspire and understand the disposition of the subjects at every question. This created greater responsibility on the interviewers than in the fertility surveys and therefore required greater cooperation between supervisors and interviewers (Ogunbodede 1998).

There was the need to specially train the interviewers the act of respect and greetings. There was need for letter of identification unlike in fertility studies. Somewhat to our surprise we found out that the respondents had more belief in university oriented research than government sponsored research. This is due to the fact that they have lost faith in their government with unfulfilled promises. This is not common in fertility surveys (Wahab 2005).

It was also noticed to our greatest amusement that older persons preferred to be interviewed when at least one of their wards is around. The reason being to remind them of certain things when in need. This had failed in several fertility studies(Akeredolu-ale 2003; Wahab 2005).

In early fertility studies it was the norm for the supervisors to check with the interviewers the location of the sampled household to complete schedules and a time re-interview the subject to check facts. This is not possible in older person's studies because it could generate hostilities (Bankole 2000).

The above modification of the practices in fertility research raised questions of central importance with regard to the verification of the research. The fundamental problem was that it was difficult to locate the older person children for interview. Three different approaches have so far been taken (Wahab 2005).

The first has been the need to return to the extended families members who live with the elderly person. It was felt that they could supply the needed data since they lived together. Yet this posed further epistemological problem because the older person may not confide fully in such person.

The second method of verification, employed by this writer to collect data was the addition of a series of questions on their children occupation, coping mechanisms, place of care when sick, 
relationship with children's partners among others.

The third method of verification aimed at checking the facts and figures of the respondents due to falling memory. This requires the use of certain events, which they remember more than dates. All the above constitute epistemological advances that are uncommon in the study of fertility and even migration. This is one of the reasons why gerontological researches can be time consuming and eventfuls.

Studying the Ijebu of Southwestern Nigeria

This happens to be the first doctoral work on the older persons to be completed. We found it necessary to include more female older persons than their male counterparts. Part of the reasons is that poverty is more profound among the former than the latter. We also found it necessary to pay repeated calls to the same household to complete a schedule. We as well found it appealing to visit the old peoples homes in the area. Later, when the study was in progress, we found that the older persons who worked in the informal sectors were economically better than those who worked in the formal sectors. Thus affirming findings in (Adegbagbo 1978; UNFPA 1998)

An earlier research conducted in 2002 by Akeredolu-Ale provided little insights due to some methodological problems.

This study used methods comprising questionnaire, focus groups discussions and in-depth interviews. It also had ancillary instruments like case histories and document analysis. This combination of several (quantitative and qualitative) methods of data collections, known as triangulation was expected to provide data on both social gerontology and demography of ageing. It was also informed by the need to integrate anthropological paradigm, with demographic approaches and sociological perspectives.

It is in the thinking of the researcher that such combination was necessary because a single instrument was incapable of traversing complex social realities. It was required to compensate for the individual weaknesses inherent in each method. This orientation in research is not limited to the eclectic choice of instruments alone, but has implication for the development of theoretical and conceptual schemes in demography of ageing. The study was also heuristic, as depicted in its findings.

Quantitative and qualitative methods were exhaustively used. Ordinarily, the structured interview helps to generate standardized information from a representative sample of a given population. It may be used exclusively when the investigation is not heuristic or when there is no need to relate findings to the socio-cultural environment. In contrast to quantitative methods, however, qualitative research methods are flexible, thus, lively, in depth, and rapid assessment into an unfamiliar, uncharted research terrain like demography of ageing (Khasarni 1991; NPC 1994). They are used to enhance the quality of findings supplied by the survey instrument, and to imbue them with greater explanatory significance.

Qualitative methods are more or less free from what has been described as "the strait jacket of prior design decisions" (Abel-smith 1991: 203). They are so flexible that they can be applied even when these design decisions are severely challenge in the open field. They facilitate the need to follow new research leads, reconstruct previously unanticipated developments, and integrate the outcomes with the research design.

In terms of analysis, the unit of analysis was the individual older person. The qualitative data analysis involved the transcription and translation of each focus group discussion and in-depth interviews. It involved the use of ethnographic summary and systematic coding through the content analysis. On the other hand, the quantitative data analysis involved data entry, data cleaning, data classification and data transformation of some variables and the use of Statistical Package for the Social Sciences (SPSS). There were three levels of analyses namely univariate, bivariate and multivariate (Wahab 2005).

\section{WORLD AGEING POPULATION}

By 1970, the population aged 60 and above in less developed regions was distinctly larger than in more developed regions although the female category was about the same. By 2020, the large numbers of older persons in less developed regions will not only be substantially more than double those in more developed countries but will comprise over 40 million more women than men (UNFPA 1998). Over 80 percent of the older persons, both male and female in less developed region will then be located in Asia. In 1995, the population aged 80 and above is still concentrated in more developed regions; and it is the large female numbers which account for this. (see Table 
Table 1:

\begin{tabular}{|c|c|c|c|c|c|c|}
\hline \multirow[t]{2}{*}{ Area/Country } & \multicolumn{2}{|c|}{1970} & \multicolumn{2}{|c|}{1995} & \multicolumn{2}{|c|}{2020} \\
\hline & Male & Female & Male & Female & Male & Female \\
\hline World & 137 & 174 & 242 & 300 & 461 & 546 \\
\hline More Developed Regions & 59 & 87 & 88 & 127 & 132 & 174 \\
\hline Less Developed Regions & 77 & 87 & 154 & 173 & 329 & 372 \\
\hline Least Developed Regions & 7 & 8 & 13 & 15 & 28 & 32 \\
\hline Africa & 8 & 10 & 16 & 19 & 37 & 42 \\
\hline Asia & 65 & 73 & 133 & 148 & 273 & 306 \\
\hline Europe & 40 & 62 & 54 & 83 & 75 & 104 \\
\hline Latin America \& Caribbean & 9 & 10 & 16 & 19 & 36 & 45 \\
\hline North America & 14 & 18 & 21 & 28 & 37 & 45 \\
\hline Oceania & 1 & 1 & 2 & 2 & 3 & 4 \\
\hline
\end{tabular}

Source: The Sex and Age Distribution of the World Population. The 1996 Revision Department of Economic and Social Affairs, Population Division, United Nations.

1). By 2020, however, the predominance of the less developed regions as the main locale of the older persons will have prevailed at these ages also, for both men and women.

Again, at these older ages, most of the older persons identified, as living in less developed regions will be in Asia: the projections indicate this concentration to be about 88 percent for each sex. In fact, it is anticipated that more than half of the males and about 46 percent of the females aged 80 and over worldwide, will be living in Asia.

\section{FURTURE RESEARCH}

Apart from improving the methodology which has been developed for studying demography of ageing in the developed countries. There is clearly a range of new matters to be researched. Much more work must be done on the economic implication of ageing. The writer once wrote on the social and economic security of older persons. The study suggests that the major impact is on the immediate family system and the need to revamp the extended family system. The study discovered the growing trend towards nuclearisation of the family structure with greater implication on the health status of the older persons, thus affirming findings in Manton (1996). In fact, research had hardly begun on the demographic implication of ageing with obvious implication on population pyramid. There are various studies on youthful population, adolescent population and even the adult population but nothing on the epistemological issues in demography of ageing and very little on situation of older persons.

The major new field for investigation will probably be the impact of ageing. In the longer term, the chief thrust must be to measure the impact of old age on the older persons.

As Treas and Logue (1986) have indicated, the status of older individuals decline with development. Older people may be considered as a low priority in development and thus can be viewed as victims of the development process. The challenge will be to simultaneously move toward formal support system of income maintenance and to maintain family support as the major informal support system. The conclusion derivable from the above is that the welfare of the elderly is hampered mainly by lack of governmental will. Therefore, the elderly are left too the whims and caprices of their families for care. This constitutes a justification for the study in Nigeria.

\section{REFERENCES}

Abel-Smith B 1991. The Beveridge Report: Its Origins and Outcomes. ISSR, 45, No. 1-2, pp. 5-16.

Adebagbo SA 1978. Social Realities and Response of Social Work Education in Africa. Paper Presented at the Third Conference and General Assembly of the Association of Social Work Education in Africa, Addis Ababa, April 5-12.

Akeredolu-Ale D 2003. Social Change, Economic Crisis and the Situation and Well-Being of the Elderly and the Aged in Nigeria. Ibadan: KPS.

Bankole SA 2000. Gender Perception of Fertility Preferences and Motivations Among Yoruba of Nigeria. In: JA Ebigbola, EP Renne (Eds): Population and Development Issues, Ideas and Debates. Ibadan: African Book Builders, pp. 173-199.

Bledsoe C, Isiugo-Abanihe UC 1989. Strategies of Child Fosterage among Mendegrannies in Sierra Leone. In: R Lestaeghe (Ed.): African Reproduction and Social Organisation. Berkeley: University of California Press, pp. 442-474.

Coombes Y 1995. Population Ageing: The Implications for Africa. African Health, 17(6): 22-3. 
Cowgill DO, Holmes L 1972. Ageing and Moderni-sation. New York: Appleton - Century Crifts.

Dixon-Mueller C, Germain H 2000. Caring for the Elderly in Ghana: Present and Future Policy Challenges Ghana. A Country Profile, 1(3). Accra: Ghana.

Hermalin AI 1995. Patterns of Support Among the Elderly in Taiwan and their Policy Implications. Paper read at the Annual Meeting of the Population Association of America, Toronto, Canada, May 3 $5,1995$.

Hernandez R 1992. Demography of Ageing. BOLD: 2(4): 8-12.

ILO 1997. Social Security Report. Geneva: International Labour Organisation (Edited by Civilian, C. et al)

Isiugo-Abanihe UC 1998. Male Contraception in Nigeria: Differentials, patterns and Motivation for Condom Use. African Population Studies, 13(1): 83-88.

John B 2000. Ageing in Society: An Introduction to Social Gerontology. London: Sage Publications.

Khasiani SA 1991. The Role of the Family in Meeting the Social and Economic Needs of the Ageing Population in Kenya. Genus, 43(1-2): 103-120.

Kinsella KG 1990. Living Arrangements of the Elderly and Social Policy: A Cross-National Perspectives. CIR Staff Pages No. 2, Center for International Research. Washington, DC: Bureau of the Census.

Mangen DJ, Bengston L 1998. Measurement of Intergenerational Relations. Newbury Park, C.A: Sage.
Manton KG, Wordbury MA 1996. Conceptual and Measurement Issues in Assessing Disability Cross Nationality: Analysis of a WHO-Sponsored Survey of the Disablement in Indonesia. Journal of CrossCultural Gerontology, 1: 339-362.

National Population Commission 1994. Census 1991: National Summary. Lagos: National Population Commission.

National Population Commission 2000. National Demographic and Health Survey 1999. Abuja: NPC.

Ogunbodede AJ 1998. Socio-Cultural Aspects of Ageing. In: SO Babalola (Ed.): Fundamentals of Sociology. Lagos: Lagos State University Press.

Togonu-Bickersteth F 1995. Gerontology in Nigeria: Filling an Academic Gap. Ife Psychology, 3:106-117.

Togonu-Bickersteth F 1997. Gender differences in expressed satisfaction with care from adult children among older rural Yoruba. Southern African Journal of Gerontology, 6(1): 3-6.

Treas J, B Logue 1986. Economic Development and the Older Population. Population and Development Review, 12(4):645-673.

UNFPA 1998. World Urbanisation Prospects. The 1996 Revision No 14. New York: UNFPA

Wahab EO 2005. Social and Economic Security of the Elderly in Nigeria, Ph D Thesis (unpublished), Ibadan: University of Ibadan. 